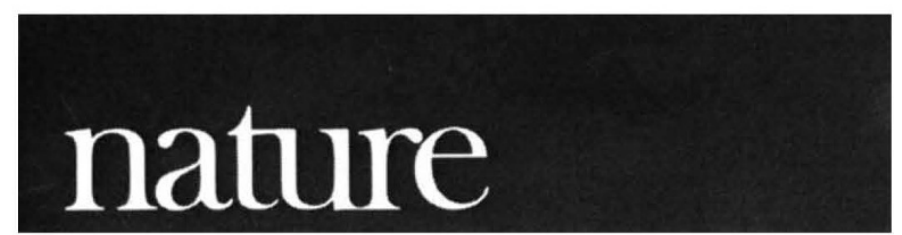

Volume 247

January 25, 1974

\section{Seven questions for the energy secretary}

Britain now has a Department of Energy whose Secretary of State is Lord Carrington, previously Secretary of State for Defence. The brief of this new department is, in the words of the Prime Minister, "to concentrate on the development of the coal industry on nuclear power and on our offshore oil and gas resources at home, as well as on those tasks of working together with other oil-consuming countries and with the oil-producing countries on the international aspects of the energy problem".

The following energy issues will ultimately deserve his or his successor's attention.

How permanent is the department to be? It is unlikely that the problem of finding adequate, rcasonably priced energy sources is going to go away before the turn of the century. Many scientists and technologists could become enthused by the thought of a long term commitment to a strong government department pursuing such desirable objectives as rethinking energy strategy. They could not face, however, being pushed around from ministry to ministry each time the Cabinet was reshuffled.

Can energy be removed from the political arena? There are many aspects of energy policy which merit serious discussion but the subject can easily become a political football. The inferior quality of the recent Commons debate on the fuel shortage does not bode well for informed non-partisan discussion in the future. Lord Carrington is, of course, a political creature holding simultaneously the post of Chairman of the Conservative Party. At the moment he is probably as obsessed with the thoughts of election strategies as with energy policy and in the long run it is desirable, assuming he wishes to remain as Secretary of State for Energy, that he does not divide his talents, particularly with such a politically exposed position.

Can some order be brought into research funding? Some weeks ago we reported on an energy strategy devised for the United States $(246,370 ; 1973)$. An important feature of it was that it was not intended to be competitive. Funding for coal was not to be at the expense, say, of funding for validating the nuclear option, nor was the coal industry in the process of its research expected to denigrate the nuclear industry. A strong impression left by many British pronouncements is that developments are largely made for this very purpose. It is therefore highly desirable that an urgent new look at funding mechanisms be made, in order to impose, if necessary, a degree of overlordship by an energy department.

Consequent on this, why not a think tank? Britain is not short of experts in almost all individual fields of energy research and use. It is, however, desperately lacking in people with wider vision. The reasons need not be repeated here. Yet without such people, and they should not necessarily be civil servants, an unreasonable load is placed on a minister in making decisions. A think tank would at least be a means of educating a wider range of people in strategic thinking.

Cannot conservation efforts be improved? Remarkably little has been done in the way of education for saving fucl and yet there are very attractive opportunitics. Why does Lord Carrington not visit a power station and invite, in front of television camcras, all viewers to turn off something electrical? The drama of a meter needle moving under the influence of one's own action in the home would rival $\mathrm{Mr}$ Geller's activities.

How will Britain react to the Kissinger energy initiative? At the same time that it was being 'warmly welcomed', Britain and France were doing bilateral deals wherever possible-deals which, however desirable in the short term, cannot have a long term future within the spirit of international cooperation. However cynical one may be about the United States leading such an initiative while consuming energy so greedily and often wastefully, in the long run someone had to recognise that energy is so much a supranational and supra-oil company affair that it has to be dealt with internationally.

And, this being so, should Britain take steps to safeguard the interests of other countries, particularly developing ones, for whom increased energy prices are much more economically damaging than for industrialised countries? The early formulation of an international attitude to energy is possibly the most urgent need there is today. It will be of great interest to see whether the big cnergy consumers can see beyond their own industrial landscape.

\section{0 years ago}

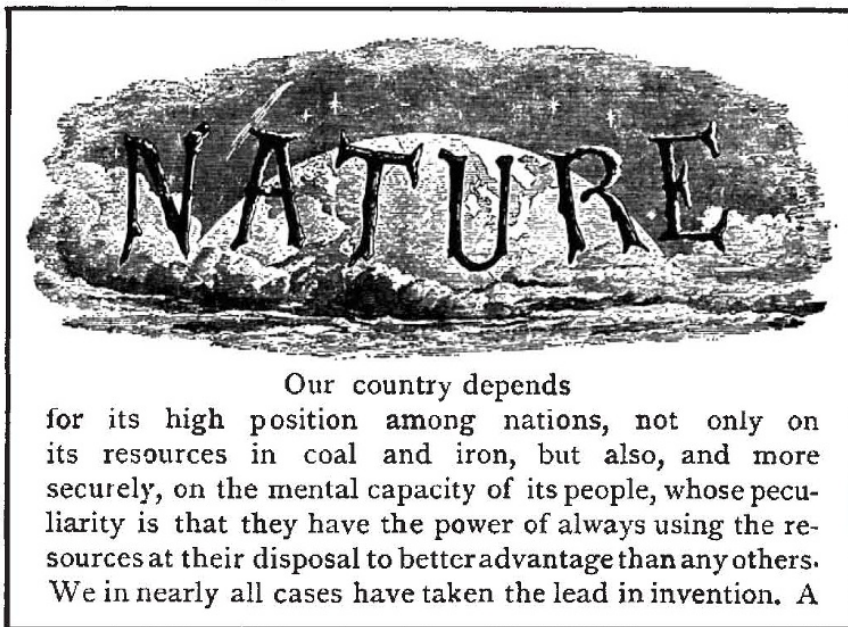

From Nature, 9, 237, January 29, 1874. 